\title{
Establishment and characterization of cell lines derived from complete hydatidiform mole
}

\author{
EIKO YAMAMOTO ${ }^{1,2}$, KAORU NIIMI $^{1}$, TOHRU KIYONO ${ }^{3}$, TOSHIMICHI YAMAMOTO ${ }^{4}$, \\ KIMIHIRO NISHINO $^{1}$, KENICHI NAKAMURA ${ }^{1}$, TOMOMI KOTANI $^{1}$, HIROAKI KAJIYAMA $^{1}$, \\ KIYOSUMI SHIBATA $^{1}$ and FUMITAKA KIKKAWA ${ }^{1}$
}

\begin{abstract}
Departments of ${ }^{1}$ Obstetrics and Gynecology and ${ }^{2}$ Healthcare Administration, Nagoya University Graduate School of Medicine, Nagoya 466-8550; ${ }^{3}$ Division of Carcinogenesis and Cancer Prevention, National Cancer Center Research Institute, Tokyo 104-0045; ${ }^{4}$ Department of Legal Medicine and Bioethics,

Nagoya University Graduate School of Medicine, Nagoya 466-8550, Japan
\end{abstract}

Received March 15, 2017; Accepted July 5, 2017

DOI: 10.3892/ijmm.2017.3067

\begin{abstract}
Gestational trophoblastic diseases (GTDs) are a group of diseases characterized by abnormal cellular proliferation of atypical trophoblasts. A hydatidiform mole is an abnormal pregnancy caused by genetic fertilization disorders, and it can be classified as a complete hydatidiform mole (CHM) or a partial hydatidiform mole. The aim of this study was to establish cell lines from CHMs and to characterize the cells for future studies concerning GTD. HMol1-2C, HMol1-3B, HMol1-8 and HMol3-1B were established from primary cultures of $\mathrm{CHM}$ explants following the introduction of different combinations of genes including human telomerase reverse transcriptase (hTERT), a mutant form of CDK (CDK4R24C), cyclin D1, p53C234, MYC and HRAS HMol1-2C, HMol1-3B, and HMol3-1B were confirmed to originate from trophoblasts of androgenic, homozygous CHMs. These three cell lines exhibited low human chorionic gonadotropin secretion, low migration and invasion abilities, and the potential to differentiate into syncytiotrophoblastic cells via forskolin treatment. These results suggest that these cells exhibit characteristics of trophoblastic cells, especially cytotrophoblastic cells. HMol1-8 was found to consist of diploid cells and originated from maternal cells, suggesting that they were derived from decidual cells. In conclusion, we
\end{abstract}

Correspondence to: Dr Eiko Yamamoto, Department of Obstetrics and Gynecology, Nagoya University Graduate School of Medicine, 65 Tsurumai-cho, Showa-ku, Nagoya 466-8550, Japan

E-mail: yamaeiko@med.nagoya-u.ac.jp

Dr Tohru Kiyono, Division of Carcinogenesis and Cancer Prevention, National Cancer Center Research Institute, 5-1-1 Tsukiji, Tyuo-ku, Tokyo 104-0045, Japan

E-mail: tkiyono@ncc.go.jp

Key words: androgenic, cell line, complete hydatidiform mole, cytotrophoblast, immortalization, primary culture successfully established three cell lines from CHMs by introduction of hTERT and other genes. Analysis revealed that the genetic origin of each cell line was identical with that of the original molar tissue, and the cell lines exhibited characteristics of trophoblastic cells, which are similar to undifferentiated cytotrophoblasts.

\section{Introduction}

Gestational trophoblastic diseases (GTDs) are a group of diseases characterized by abnormal cellular proliferation of atypical trophoblasts and include hydatidiform moles, invasive moles, choriocarcinomas, placental site trophoblastic tumors, and epithelial trophoblastic tumors. A hydatidiform mole is an abnormal pregnancy caused by genetic fertilization disorders, and it can be classified as a complete hydatidiform mole (CHM) or a partial hydatidiform mole (PHM). CHMs are androgenic in origin and occur through fertilization of an ovum with an inactivated or eliminated nucleus, with two sperms (dispermy) or with a haploid sperm followed by duplication of its chromosomes $(1,2)$. PHMs are biparental and are generally dispermic triploids $(3,4)$. Hydatidiform moles, especially CHMs, have a high potential to develop into cancer, with invasive moles developing in $15-24 \%$ of CHM cases (5-7). The risk associated with choriocarcinoma is 2,000-4,000 times higher in hydatidiform moles than in normal pregnancy or abortion (2).

Previous studies on hydatidiform moles have examined the genes or proteins involved using tissues of hydatidiform moles. Investigation into the function of trophoblasts of hydatidiform moles has not been performed and is largely limited by the short life spans of primary cultured trophoblasts in vitro. A cell line established from a hydatidiform mole would allow for investigation into the function of molar trophoblasts. The cell line CHM1 was established from CHM and has been used only for genomic studies making use of characteristics of a single haplotype $(8,9)$. Because a hydatidiform mole is a type of pregnancy, it is difficult to maintain a primary culture of growing non-cancerous trophoblasts for more than a few weeks. There are, however, previous studies that have established cell lines from normal human or 
animal cells using a transfection technique involving human telomerase reverse transcriptase (hTERT), as well as mutant forms of CDK (CDK4R24C) and cyclin D1 (10-12). The gain in telomerase activity obtained through expression of hTERT was found to be insufficient to make a cell line derived from normal cells immortal (13). The aim of this study was to establish cell lines from CHMs and to characterize the cells for future studies on hydatidiform moles and gestational trophoblastic neoplasia.

\section{Materials and methods}

Tissue collection and processing. This study was approved by the Ethics Committee of Nagoya University Graduate School of Medicine. CHM tissues were obtained from patients who had undergone evacuations at 8-10 weeks of gestation $(n=6)$. CHM diagnoses were confirmed by pathological examination. Intraoral cells were obtained by OmniSwab (GE Healthcare, Chicago, IL, USA) from two of the CHM patients and their husbands for short tandem repeat (STR) analysis. Informed consent was obtained from the patients and their husbands for the use of the molar tissues and their intraoral cells.

Cell line and antibodies. Human choriocarcinoma cell line Jar was purchased from the American Type Culture Collection (Manassas, VA, USA) and was grown in RPMI-1640 medium (Sigma-Aldrich, St. Louis, MO, USA) supplemented with $10 \%$ FCS, penicillin $(100 \mathrm{U} / \mathrm{ml})$, streptomycin $(100 \mu \mathrm{g} / \mathrm{ml})$, and $2 \mathrm{mM}$ glutamine. Cultures were incubated at $37^{\circ} \mathrm{C}$ in $5 \% \mathrm{CO}_{2}$. Anti-hCG antibody (Ab) (N1534, rabbit polyclonal), anti-human placental lactogen (hPL) Ab (A0137, rabbit polyclonal), and anti-human cytokeratin 7 (CK7) Ab (ready-to-use $\mathrm{N}$-series, mouse monoclonal) were purchased from Dako (Glostrup, Denmark). Anti-CK8/18 Ab (MM-1700-01, mouse monoclonal) was purchased from ImmunoBioScience (Mukilteo, WA, USA) and anti-vimentin Ab (ready-to-use $\mathrm{N}$-series, mouse monoclonal) was purchased from Nichirei Biosciences Inc. (Tokyo, Japan).

Human CHM explant culture. Molar explant culture was established using molar tissues obtained from evacuations (8-10 weeks, $n=6)$. Molar tissues were washed with phosphate-buffered saline (PBS) and aseptically dissected to remove blood and decidual tissues, and then only molar vesicles were collected. After teasing apart small fragments of molar vesicles, molar fragments were placed in collagen type I-coated dishes (BD Biosciences, Franklin Lakes, NJ, USA) and incubated in Dulbecco's modified Eagle's medium (DMEM) (Wako, Osaka, Japan) supplemented with $10 \%$ FCS, penicillin $(100 \mathrm{U} / \mathrm{ml})$, streptomycin $(100 \mu \mathrm{g} / \mathrm{ml})$, and $5 \%$ amphotericin $\mathrm{B}$ at $37^{\circ} \mathrm{C}$ in a $5 \% \mathrm{CO}_{2}$ atmosphere. Detached cells and molar fragments were removed after incubation for $24 \mathrm{~h}$, and medium was changed every $48 \mathrm{~h}$ until use in examinations.

Immunocytochemistry. Molar explants, which were cultured for 3 days, and cells were used for immunocytochemistry. Dishes were washed gently with cold PBS, and cells were fixed with $4 \%$ paraformaldehyde for $30 \mathrm{~min}$ at room temperature and methanol for $10 \mathrm{~min}$ at $-20^{\circ} \mathrm{C}$. After blocking with
5\% skim milk in PBS for 20 min at room temperature, cells were immunostained using anti-hCG Ab (1:50), anti-hPL $\mathrm{Ab}$ (1:1,000), anti-CK8/18 Ab (1:50), anti-vimentin Ab, and anti-human $\mathrm{CK} 7 \mathrm{Ab}$ in the dilutions recommended by the manufacturer. For negative controls, the primary antibody was replaced with PBS.

Vector construction and retroviral infection. Construction of lentiviral vector plasmids CSII-CMV-hTERT, -CDK4R24C, -cyclin D1, -p53C234 and -TetOff, were described previously $(12,14)$. CDK4R24C is a mutant (p16INK4a-resistant) form of CDK4, and p53C234 encodes the carboxy-terminal 234 residues of p53 and functions as a dominant-negative mutant. Similarly, entry vectors containing cDNAs for hTERT, cyclinD1, and CDK4R24C were recombined with the lentiviral vector CSII-TRE-Tight-RfA, in which the elongation factor promoter in CSII-EF-RfA (a gift from Hiroyuki Miyoshi; Riken BRC, Tsukuba, Japan) was replaced with the tetracycline-responsive promoter from pTRE-Tight (Clontech, Mountain View, CA, USA) to generate CSII-TRE-Tight-cyclin D1, -CDK4R24C and -p53C234. CSII-TRE-Tight-MYC-2A-HRAS was constructed by recombining the wild-type MYC and HRAS cDNA segments separated by the sequences encoding the autonomous 'self-cleaving' $2 \mathrm{~A}$ peptides derived from foot-and-mouse disease virus (FMDV) (15) with CSII-TRE-Tight-RfA. Production and infection of recombinant lentiviruses was performed as described previously $(12,16)$.

Establishment of immortalized human molar cells. We used the primary-cultured molar cells from two CHM patients (10 weeks) for immortalization. The primary cells from hydatidiform mole tissue no. 1 (Mole1) were infected in $25 \mathrm{~cm}^{2}$ flasks with a combination of CSII-CMV-hTERT and -CDK4R24C (\#8); CSII-CMV-hTERT, -CDK4R24C, -cyclin D1 and -p53C234 (\#2C); or CSII-CMV-hTERT, -TetOff, CSII-TRE-Tight-CDK4R24C and -cyclin D1 (\#3B) at multiplicity of infection values of $>5$. Another batch of primary cells from hydatidiform mole tissue no. 3 (Mole3) was infected in a 12-well dish with a combination of CSII-CMV-hTERT, -CDK4R24C, -cyclin D1, -TetOff, CSII-TRE-Tight-p53C234 and -MYC-2A-HRAS (\#1B). Among several colonies growing in the dish, fibroblastic colonies were manually removed, and colonies with epithelial morphology were expanded from the culture and further characterized. HMol cell lines were cultured in Epi-Life KG2 (Kurabo Industries Ltd., Osaka, Japan) and DMEM at initial and final ratios of 4:1 and 1:1, respectively. Epi-Life KG2 was used after adding insulin $(10 \mu \mathrm{g} / \mathrm{ml})$, human epithelial growth factor (hEGF, $0.1 \mathrm{ng} / \mathrm{ml}$ ), hydrocortisone $(0.5 \mu \mathrm{g} / \mathrm{ml})$, gentamycin $(50 \mu \mathrm{g} / \mathrm{ml})$, amphotericin $\mathrm{B}(50 \mathrm{ng} / \mathrm{ml})$, and $0.4 \% \mathrm{v} / \mathrm{v}$ bovine pituitary extract (BPE).

Short tandem repeat analysis. Genomic DNA was extracted from HMol cell lines, molar tissues (Mole1 and Mole3) and intraoral cells of the two patients and their husbands. DNA (1 ng) was amplified using a commercially available kit (AmpFISTR Identifilter ${ }^{\mathrm{TM}}$ PCR amplification kit; Applied Biosystems, Foster City, CA, USA) with 15 STR markers and a gender determination marker used for personal identification and paternity tests. The amplified fragments were loaded on a PRISM Genetic Analyzer 310 and were 
automatically genotyped with GeneMapper ID software v3.2 (Applied Biosystems).

Chromosome analysis. Chromosomes from Mole3 and four HMol cell lines (HMol1-2C, HMol1-3B, HMol1-8 and HMol3-1B) were analyzed by G-band and karyotyping. The analysis used fresh tissue from Mole3 and HMol cell lines, which were cultured more than four months after gene transfection.

Cell proliferation assay. For cell proliferation assay, $5 \times 10^{3}$ cells were plated in $100 \mu \mathrm{l}$ medium in 96 -well plates. Cell viability was determined by modified tetrazolium salt (MTS) assay using the Cell Titer 96 Aqueous One Solution Proliferation assay kit (Promega, Fitchburg, WI, USA) according to the manufacturer's instructions. Data were obtained from three independent experiments with eight samples each.

Transwell migration and invasion assays. Assay of the migration and invasion abilities of Jar cells and HMol cells was performed as previously reported (17). Transwells (Corning Inc., Corning, NY, USA) with a filter of $6.5-\mathrm{mm}$ diameter and $8.0-\mu \mathrm{m}$ pore size were used. Cell numbers were adjusted to $3.0 \times 10^{5} / \mathrm{ml}$ in serum-free medium. A $200-\mu 1$ sample was added in triplicate to the upper wells, and $800 \mu \mathrm{l}$ of serum-free medium with $1 \%$ fibronectin was added to the lower wells. Assays were performed after $24 \mathrm{~h}$ of incubation. Invasion assay was performed under the same conditions as those for migration assay, except that wells were coated with Matrigel (Collaborative Biomedical Products, Bedford, MA, USA). The number of cells was counted under a microscope at x200 magnification. Data were obtained from three independent experiments and are expressed as the mean \pm standard deviation (SD).

Assay for $h C G$ and $h P L$ in the culture medium. To detect the presence of hCG and hPL in the culture medium, $5 \times 10^{4}$ cells were plated in a 24-well chamber and incubated for $24 \mathrm{~h}$. The medium was replaced with $600 \mu \mathrm{l}$ of serum-free DMEM, and cells were cultured for $48 \mathrm{~h}$. To examine the effect of forskolin treatment on hCG secretion, serum-free medium containing $20 \mu \mathrm{M}$ of forskolin (Sigma-Aldrich) was used. Conditioned media were collected, and levels of hCG and hPL were quantified in triplicate with an enzyme immunoassay (EIA) using an hCG- $\beta$-CTP Ab and a latex agglutination immunoassay (both from SRL Inc., Tokyo, Japan), respectively. Data are expressed as the mean $\pm \mathrm{SD}$.

Fluorescent staining. Cells were cultured in DMEM for $24 \mathrm{~h}$ before the medium was removed and replaced with serum-free DMEM with or without $100 \mu \mathrm{M}$ forskolin. After incubation for $48 \mathrm{~h}$, cells were fixed with $4 \%$ paraformaldehyde for $30 \mathrm{~min}$ at room temperature and permeabilized with PBS containing $0.2 \%$ Triton-X. After blocking with PBS containing 7\% fetal bovine serum (FBS) for $20 \mathrm{~min}$ at room temperature, cells were incubated with a fluorescein isothiocyanate-labeled antibody against phalloidin (R-415; Invitrogen, Waltham, MA, USA) at a dilution of 1/500 and Hoechst 33342 (Bio-Rad Laboratories, Hercules, CA, USA) at a dilution of $1 / 100$ for $1 \mathrm{~h}$. After washing with PBS, cells were analyzed using a
Biorevo BZ-8000 fluorescence microscope (Keyence, Osaka, Japan).

\section{Results}

Primary culture of molar explants and immunocytochemical expression of trophoblastic markers in cultured molar cells. We first investigated whether molar trophoblasts could be cultured and isolated from hydatidiform molar tissues using the same method as that used to isolate EVTs from human chorionic villi (18). We found that round cells started growing from the explanted molar tissue tips after $24 \mathrm{~h}$ of incubation (Fig. 1A) and that cells were able to grow for 7 days on collagen-coated dishes (Fig. 1B). To confirm the trophoblastic character of the cells, we performed immunocytochemistry using isolated molar cells after 3 days of culture. These cells exhibited positive immunoreactivity against the trophoblast markers CK7 and CK8/18 (Fig. 1C and D) (17-19). Hydatidiform moles secrete more hCG than normal pregnancies do. hPL is produced mainly by syncytiotrophoblasts and can be used as a marker of intermediate trophoblasts (20). Both hCG and hPL were expressed in isolated molar cells (Fig. 1E and F). Most cells were mononuclear cells, but some were multinuclear like syncytiotrophoblasts (Fig. 1G).

Morphological analysis of HMol cells. Cell lines were established from isolated molar cells derived from Mole1 (three lines) and Mole3 (one line) tissues following transduction of different sets of lentiviruses, including CSII-CMV-hTERT. These independent cell lines were named HMol1-2C, HMol1-3B, HMol1-8 and HMol3-1B. To create epithelial cell lines, we removed fibroblastic colonies manually and cultured the cells with medium containing Epi-Life KG2 and growth factors such as insulin, hEGF, and hydrocortisone. HMoll-2C, HMol1-3B and HMol3-1B cells exhibited two cell patterns with small cells and large cells, similar to cytotrophoblasts and syncytiotrophoblasts (Fig. 2B, D and H). In contrast, HMol1-8 cells were round and bigger than those of the other three cell lines (Fig. 2F), and it took longer to grow and remove HMol1-8 cells from dishes using trypsin compared to those of the other three cell lines. We assumed therefore that HMol1-8 cells may exhibit different characteristics than the others.

STR analysis. To confirm the genetic origins of the HMol cell lines, we performed STR analysis using DNA from the four cell lines, the two patients, their partners, and the CHM tissues (Mole1 and Mole3). The results showed that the two molar tissues each contained only one paternal allele at most loci. Although eight loci from one mother (Mother1) and nine loci from the other mother (Mother3) showed the same alleles as Mole1 and Mole3, respectively, it was clear that the two molar tissues were not biparental, suggesting that they arose from a single sperm fertilizing an empty ovum (Table I). Results from HMol1-3B and HMol1-2C were identical to that of Mole1, and HMol3-1B was genetically identical to Mole3. However, HMol1-8 contained the same alleles as the maternal cells from which Mole1 was derived. These results indicated that HMol1-3B, HMol1-2C and HMol3-1B originated from CHMs, 

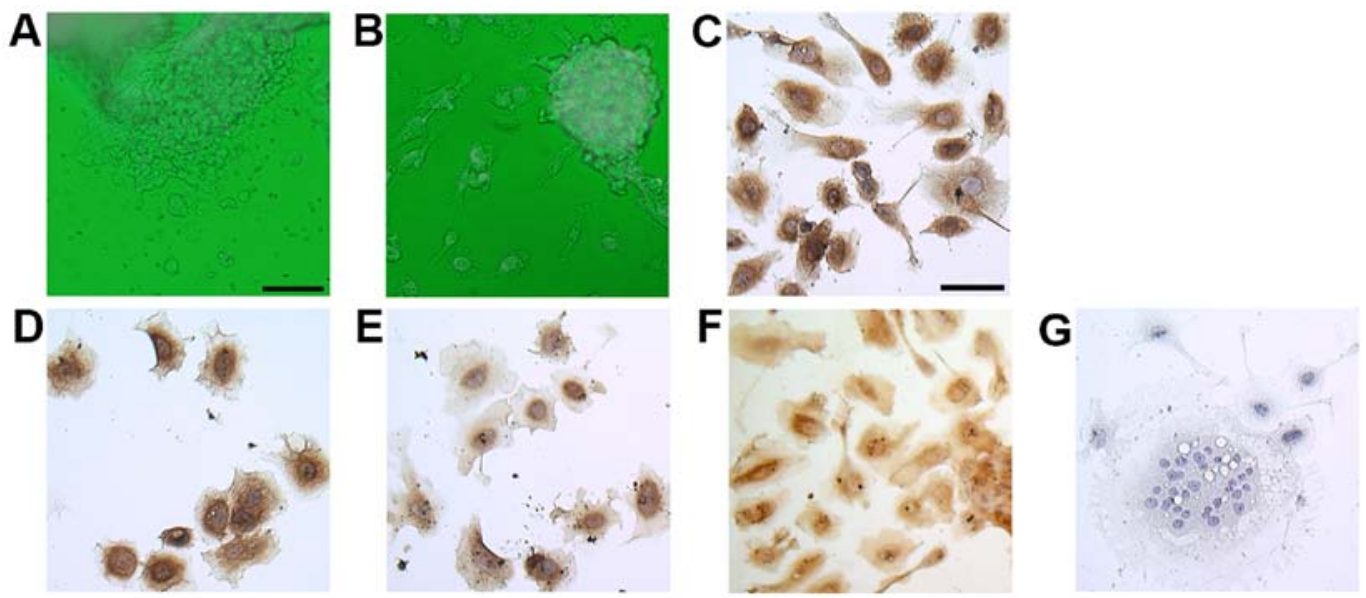

Figure 1. Primary culture of hydatidiform mole explants and immunostaining of primary culture cells with trophoblastic markers. (A) Cells started deriving from the tip of the hydatidiform mole the day after explanting. (B) Primary culture of hydatidiform mole after 7 days, exhibiting cell migration from the tips of explants. (C) Immunostaining of primary culture molar cells using anti-CK7 antibody, (D) anti-CK8/18 antibody, (E) anti-human chorionic gonadotropin (hCG) antibody, and (F) anti-human placental lactogen (hPL) antibody. The results of immunocytochemistry identified the cultured cells as belonging to the trophoblast cell population. (G) Negative control. Magnification, x100; scale bars, $100 \mu \mathrm{m}$.
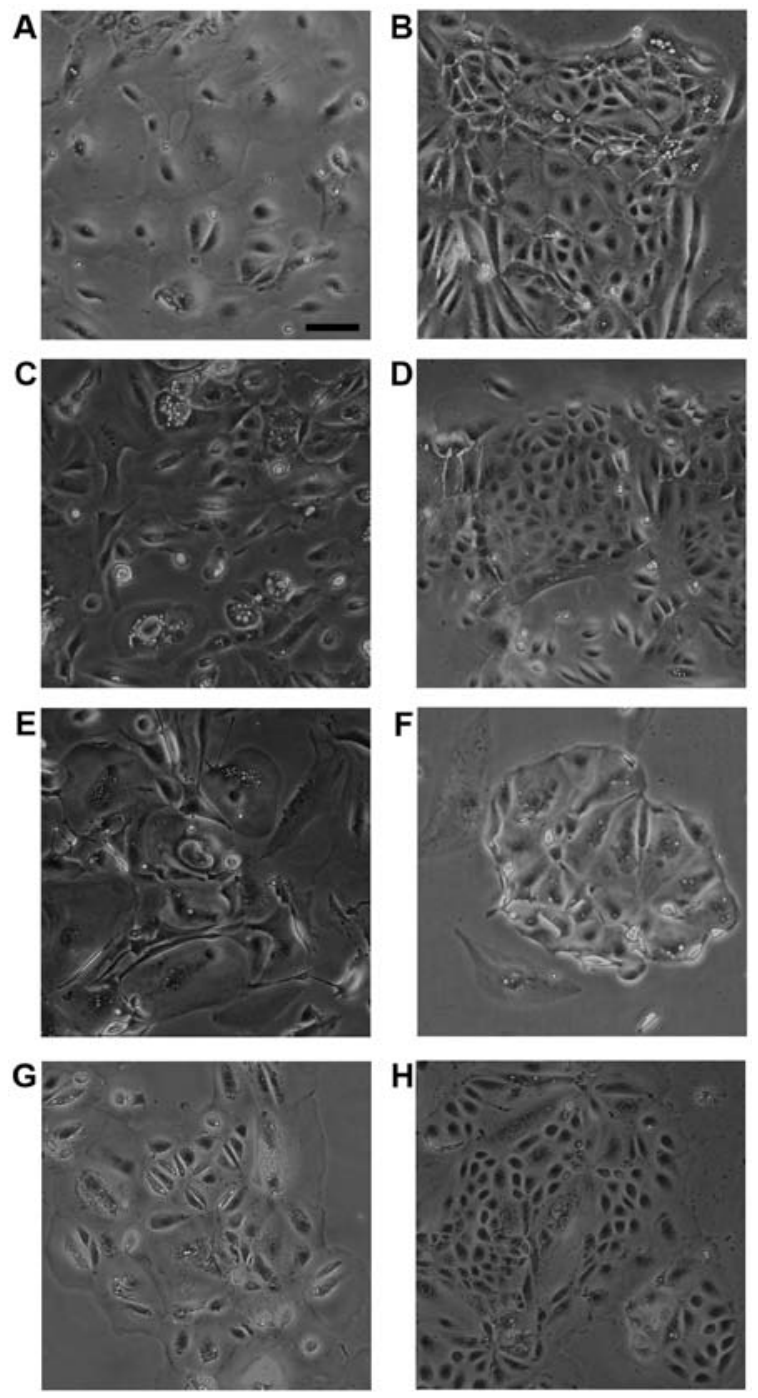

Figure 2. Established cells after transfection of four gene combinations including CSII-CMV-hTERT into the primary cultures of complete hydatidiform moles. (A) HMol1-2C (passage 2), (B) HMol1-2C (passage 29), (C) HMol1-3B (passage 3), (D) HMol1-3B (passage 20), (E) HMol1-8 (passage 2), (F) HMol1-8 (passage 22), (G) HMol3-1B (passage 3), and (H) HMol3-1B (passage 20). Magnification, x100; scale bar, $100 \mu \mathrm{m}$. but HMol1-8 was derived from the maternal cells of Mole1. The results of STR and cell morphology analyses suggested that HMol1-8 was likely established from decidual cells.

Karyotype analysis. Table II shows the results of chromosome number analysis of 100 cells from each cell line. The analysis revealed that chromosome numbers in HMol1-2C, HMol1-3B, and HMol3-1B primarily ranged from 80 to 88 (Table II), and karyotype analysis showed that most chromosomes had four bands in these three cell line. The karyotype of Mole3 was 46, XX (data not shown), and karyotype analysis of Mole1 was not performed. Lawler et al performed genetic studies of 149 CHMs, and the results showed that 128 were diploid, 1 triploid, 1 haploid, and 19 unknown (21). These results suggest that the three cell lines may have been established from tetraploid cells after duplication of diploid cells, with loss and recombination of some chromosomes. On the other hand, $81 \%$ of HMol1- 8 cells had a karyotype of $48, \mathrm{XX}$, with trisomies 2 and 5 noted in most cells. We assumed that HMoll-8 cells originated from diploid $(46, \mathrm{XX})$ cells and that the chromosomal alterations were induced during gene transduction and culture.

Immunocytochemical analysis of HMol1-2C, HMoll-3B, HMoll-8 and HMol3-1B. Next, we performed immunocytochemistry to confirm HMol1-2C, HMol1-3B and HMol3-1B as trophoblastic cells. We used the choriocarcinoma cell line Jar as a representative trophoblastic cell line for comparison with the three HMol cell lines. All three HMol cell lines showed positive staining for CK7, hCG and hPL but were negative for vimentin, similar to Jar staining patterns (Fig. 3). The results of HMol1-2C, HMol1-3B, and HMol3-1B staining are consistent with the characteristics of trophoblastic cells. Immunocytochemistry of HMol1-8 showed that the round cells were very weakly positive for CK7 and positive for hCG, $\mathrm{hPL}$, and vimentin. Although cytokeratin and vimentin are used as markers for epithelial cells and mesenchymal cells, decidual cells are reported to be positive for vimentin as well (22). These results suggest that HMol1-8 cells have the characteristics of decidual cells. 
Table I. Short tandem repeat analysis of DNA from molar tissues and established cell lines.

\begin{tabular}{|c|c|c|c|c|c|c|c|c|c|c|c|c|c|c|c|c|c|c|c|c|}
\hline \multirow[b]{2}{*}{ Marker } & \multicolumn{2}{|c|}{ Motherl } & \multicolumn{2}{|c|}{ Father1 } & \multicolumn{2}{|c|}{ Mole 1 } & \multicolumn{2}{|c|}{ HMoll-2C } & \multicolumn{2}{|c|}{ HMol1-3B } & \multicolumn{2}{|c|}{ HMol1-8 } & \multicolumn{2}{|c|}{ Mother3 } & \multicolumn{2}{|c|}{ Father3 } & \multicolumn{2}{|c|}{ Mole3 } & \multicolumn{2}{|c|}{ HMol3-1B } \\
\hline & $\begin{array}{c}\text { Allele } \\
1\end{array}$ & $\begin{array}{c}\text { Allele } \\
2\end{array}$ & $\begin{array}{c}\text { Allele } \\
1\end{array}$ & $\begin{array}{c}\text { Allele } \\
2\end{array}$ & $\begin{array}{c}\text { Allele } \\
1\end{array}$ & $\begin{array}{c}\text { Allele } \\
2\end{array}$ & $\begin{array}{c}\text { Allele } \\
1\end{array}$ & $\begin{array}{c}\text { Allele } \\
2\end{array}$ & $\begin{array}{c}\text { Allele } \\
1\end{array}$ & $\begin{array}{c}\text { Allele } \\
2\end{array}$ & $\begin{array}{c}\text { Allele } \\
1\end{array}$ & $\begin{array}{c}\text { Allele } \\
2\end{array}$ & $\begin{array}{c}\text { Allele } \\
1\end{array}$ & $\begin{array}{c}\text { Allele } \\
2\end{array}$ & $\begin{array}{c}\text { Allele } \\
1\end{array}$ & $\begin{array}{c}\text { Allele } \\
2\end{array}$ & $\begin{array}{c}\text { Allele } \\
1\end{array}$ & $\begin{array}{c}\text { Allele } \\
2\end{array}$ & $\begin{array}{c}\text { Allele } \\
1\end{array}$ & $\begin{array}{c}\text { Allele } \\
2\end{array}$ \\
\hline D8S1179 & 13 & 13 & 11 & 14 & 14 & & 14 & & 14 & & 13 & 13 & 13 & 15 & 11 & 13 & 13 & & 13 & \\
\hline D21S11 & 30 & 31.2 & 29 & 30 & 30 & & 30 & & 30 & & 30 & 31.2 & 30 & 30 & 30 & 32.2 & 32.2 & & 32.2 & \\
\hline D7S820 & 8 & 10 & 10 & 10 & 10 & & 10 & & 10 & & 8 & 10 & 8 & 11 & 8 & 8 & 8 & & 8 & \\
\hline CSFIPO & 11 & 12 & 11 & 13 & 11 & & 11 & & 11 & & 11 & 12 & 11 & 12 & 9 & 14 & 14 & & 14 & \\
\hline D3S1358 & 16 & 17 & 15 & 17 & 15 & & 15 & & 15 & & 16 & 17 & 16 & 18 & 15 & 15 & 15 & & 15 & \\
\hline TH01 & 6 & 9 & 6 & 9 & 9 & & 9 & & 9 & & 6 & 9 & 9 & 9 & 9 & 9 & 9 & & 9 & \\
\hline D13S317 & 11 & 11 & 9 & 12 & 9 & & 9 & & 9 & & 11 & 11 & 11 & 11 & 8 & 11 & 11 & & 11 & \\
\hline D16S539 & 12 & 13 & 9 & 13 & 13 & & 13 & & 13 & & 12 & 13 & 9 & 10 & 9 & 10 & 10 & & 10 & \\
\hline D2S1338 & 17 & 24 & 20 & 22 & 22 & & 22 & & 22 & & 17 & 24 & 18 & 23 & 24 & 26 & 26 & & 26 & \\
\hline D19S433 & 13 & 14 & 14 & 14.2 & 14 & & 14 & & 14 & & 13 & 14 & 14 & 14.2 & 14 & 14 & 14 & & 14 & \\
\hline vWA & 16 & 18 & 16 & 17 & 16 & & 16 & & 16 & & 16 & 18 & 18 & 18 & 16 & 20 & 16 & & 16 & \\
\hline TPOX & 8 & 8 & 11 & 12 & 11 & & 11 & & 11 & & 8 & 8 & 8 & 11 & 8 & 9 & 9 & & 9 & \\
\hline D18S51 & 14 & 14 & 13 & 16 & 13 & & 13 & & 13 & & 14 & 14 & 13 & 16 & 14 & 17 & 14 & & 14 & \\
\hline AMEL & $\mathrm{x}$ & $\mathrm{x}$ & $\mathrm{x}$ & $\mathrm{Y}$ & $\mathrm{x}$ & & $\mathrm{x}$ & & $\mathrm{x}$ & & $\mathrm{x}$ & $\mathrm{x}$ & $\mathrm{x}$ & $\mathrm{x}$ & $\mathrm{x}$ & $\mathrm{Y}$ & $\mathrm{x}$ & & $\mathrm{x}$ & \\
\hline D5S818 & 12 & 14 & 9 & 13 & 13 & & 13 & & 13 & & 12 & 14 & 12 & 12 & 12 & 13 & 12 & & 12 & \\
\hline FGA & 22 & 24 & 20 & 21 & 21 & & 21 & & 21 & & 22 & 24 & 22 & 24 & 22 & 22 & 22 & & 22 & \\
\hline
\end{tabular}

Light gray cells and dark grey cells represent allele of mother and molar tissue, respectively.

Table II. Karyotype analysis of the newly established cell lines.

\begin{tabular}{|c|c|c|c|c|c|c|c|c|c|c|c|c|c|c|c|}
\hline \multirow[t]{2}{*}{ HMol1-2C } & No. of chromosomes & $\leq 77$ & 78 & 79 & 80 & 81 & 82 & 83 & 84 & 85 & 86 & 87 & $88-99$ & $\leq 100$ & Total \\
\hline & No. of cells & 14 & 2 & 6 & 8 & 11 & 11 & 16 & 10 & 3 & 5 & 1 & 4 & 9 & 100 \\
\hline \multirow[t]{2}{*}{ HMol1-3B } & No. of chromosomes & $\leq 79$ & 80 & 81 & 82 & 83 & 84 & 85 & 86 & 87 & 88 & 89 & $90-99$ & $\leq 100$ & Total \\
\hline & No. of cells & 6 & 1 & 0 & 4 & 5 & 15 & 13 & 14 & 15 & 8 & 4 & 7 & 9 & 100 \\
\hline \multirow[t]{2}{*}{ HMol1-8 } & No. of chromosomes & $\leq 46$ & 47 & 48 & 49 & 50 & 51 & 94-98 & Total & & & & & & \\
\hline & No. of cells & 2 & 3 & 81 & 2 & 1 & 0 & 11 & 100 & & & & & & \\
\hline \multirow[t]{2}{*}{ HMol3-1B } & No. of chromosomes & $\leq 79$ & $80-81$ & 82 & 83 & 84 & 85 & 86 & 87 & $88-100$ & $168 \pm$ & Total & & & \\
\hline & No. of cells & 7 & 0 & 9 & 12 & 15 & 20 & 13 & 3 & 2 & 9 & 90 & & & \\
\hline
\end{tabular}

Cell proliferation. Cell proliferation of the four established cell lines was examined by MTS assay. Cell growth was fastest in the HMol1-3B cells, and HMol1-2C and HMol3-1B cells grew nearly at the same speeds. HMol1-8 cells grew very slowly, with only a $17.0 \%$ increase after $72 \mathrm{~h}$ of incubation (Fig. 4A).

Migration and invasion assays. We next examined whether the three cell lines originating from CHMs have the same migration and invasion abilities as Jar cells $(18,23)$. While cells from the three cell lines did migrate, the migrated cell numbers were much lower than those of Jar cells. Migration ability was strongest in HMol1-2C and weakest in HMol3-1B (Fig. 4B, left panel). Invasion assay showed that HMol1-2C and HMol1-3B cells possessed invasion abilities, but these were much weaker than those of the Jar cells (Fig. 4B, right panel). HMol3-1B cells underwent very little invasion under the same condition as those of the other cell lines. We assumed that the migration and invasion abilities of the molar cell lines were weaker than those of Jar cells because hydatidiform moles are a type of pregnancy while Jar cells are established from choriocarcinoma.
Differentiation ability of HMol cells after forskolin treatment. The characteristics of trophoblastic cells include proliferation, migration, invasion and hormone production, and these depend on the type and differentiation of the trophoblasts involved. Immunocytochemistry showed that HMol1-2C, HMol1-3B and HMol3-1B cells expressed hCG and hPL (Fig. 3). To identify additional characteristics of the three cell lines, we measured secretion levels of hCG and hPL and examined the effects on the cells of forskolin treatment, which is used for differentiation of trophoblasts in vitro. Levels of hPL in conditioned media were $<0.05 \mathrm{mg} / \mathrm{ml}$ in all three molar cell lines and in Jar cells. Secretion of hCG was stimulated by forskolin treatment in all three molar cell lines as well as in Jar cells, although basal and induced levels of hCG in molar cell lines were much lower than those in Jar (Fig. 4C). Interestingly, the molar cell line with the highest migration ability (HMol1-2C) had the lowest level of hCG secretion. An increase in hCG secretion suggests that forskolin treatment may induce the molar cell lines to differentiate into syncytiotrophoblastic cells. Immunofluorescent double-staining for nuclei (Hoechst) and the actin cytoskeleton (phalloidin) was performed to visualize the number of nuclei in each cell as well as cell 

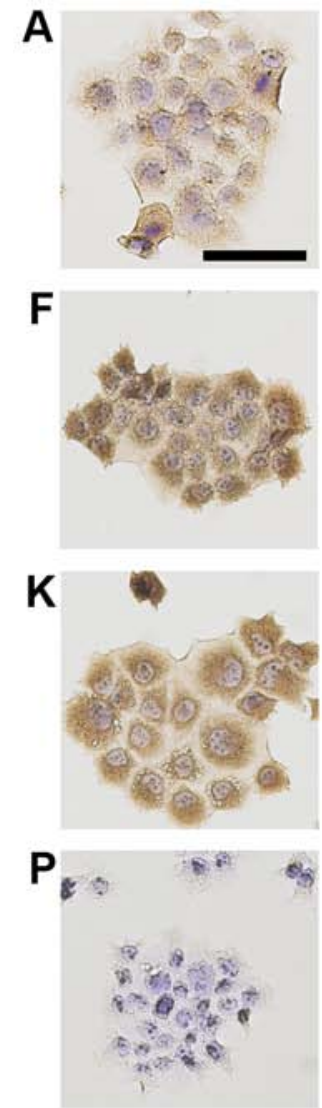

B
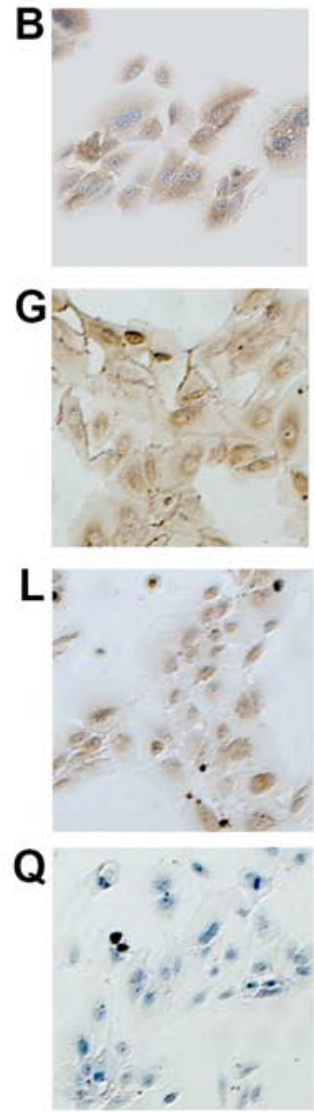

C
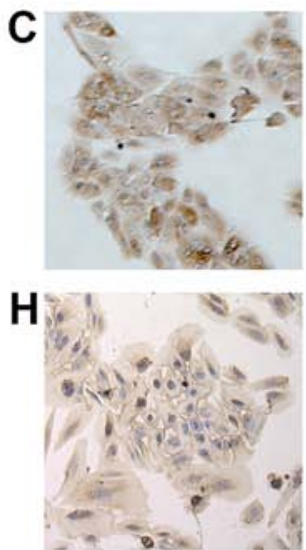

M

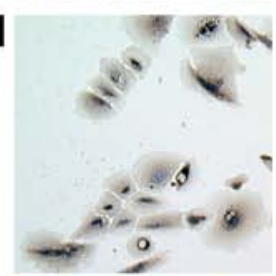

$\mathbf{R}$

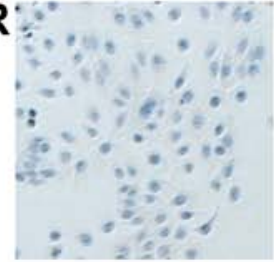

D
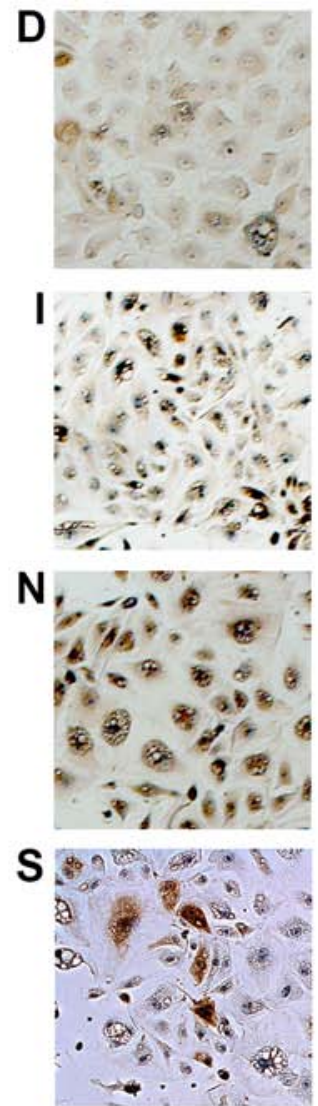
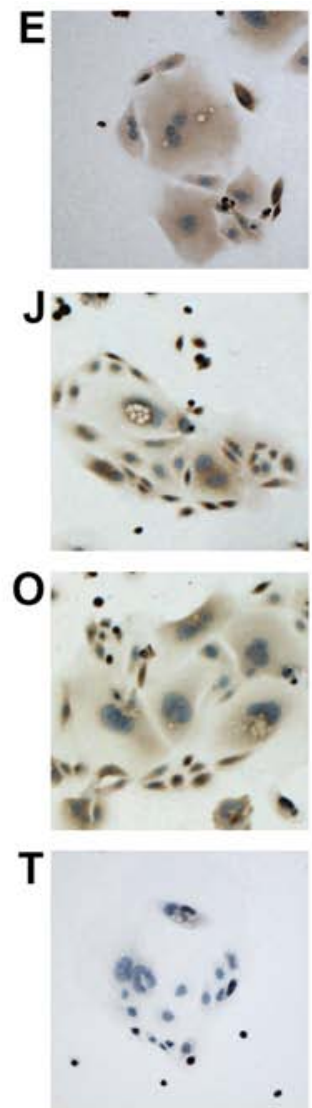

Figure 3. Immunocytochemistry of cell lines established from primary cultures of complete hydatidiform moles compared with that of a choriocarcinoma cell line, Jar. Immunostaining of Jar with (A) CK7, (F) human chorionic gonadotropin (hCG), (K) human placental lactogen (hPL), and (P) vimentin. Jar was positive for CK7, hCG and hPL and negative for vimentin. Immunostaining of (B, G, L and Q) HMol1-2C, (C, H, M and R) HMol1-3B, (D, I, N and S) HMol1-8 and (E, J, O and T) HMol3-1B, using antibodies against (B-E) CK7, (G-J) hCG, (L-O) hPL and (Q-T) vimentin. Magnification, x100; scale bar, 100 $\mu$ m.

borders (Fig. 4D). We used HMol3-1B cells to examine the effect of forskolin on cell fusion because among the three lines, this cell line showed the highest hCG secretion with forskolin treatment. HMol3-1B cells became multi-nucleated after incubation for $48 \mathrm{~h}$ with $100 \mu \mathrm{M}$ forskolin (Fig. 4D). These results suggest that treatment with forskolin upregulates differentiation and fusion of HMol3-1B cells.

\section{Discussion}

In the present study, three cell lines (HMol1-2C, HMol1-3B and HMol3-1B) were established and confirmed to originate from CHM trophoblasts. STR analysis revealed that HMol1-2C, HMol1-3B and HMol3-1B were genetically identical to their corresponding Mole1 and Mole3 progenitors. HMol1-2C, HMol1-3B and HMol3-1B cells were thus considered to have characteristics of cytotrophoblasts rather than differentiated trophoblasts such as syncytiotrophoblasts and EVTs. The three cell lines showed low levels of hCG secretion and low cell invasion abilities; hCG is mainly produced by syncytiotrophoblasts and EVTs have invasion ability. The observed increases in cell fusion and hCG secretion following forskolin treatment is consistent with the characteristics of cytotrophoblasts, which can differentiate into syncytiotrophoblasts. In the primary culture of molar tissues, small, round cells first derived from the tips of molar explants, and then some spindle-shaped, EVT-like cells appeared around day 7. Some multi-nucleated, syncytio- trophoblast-like cells were found during primary culture. After establishment of HMol cell lines, the number of multi-nucleated cells diminished, and more small cells were noted in later passages. These results suggest that the major constituents of the three cell lines may exhibit characteristics of cytotrophoblasts.

We established HMol1-8, which may have originated from decidual cells. STR analysis revealed that HMol1-8 was derived from maternal cells. Decidual and squamous cells of the uterine cervix and the vagina were considered to be contaminants. Decidual cells may inadvertently be included with the molar vesicles since the tips of the villi are attached to the decidua basalis with fibrinoids. Surface cells of the uterine cervix and the vagina may act as contaminants during operations. The HMol1-8 cell line consisted of large round cells that showed positive immunoreactivity for vimentin. Squamous cells are epithelial cells that are positive for cytokeratin, and decidual cells express vimentin because they are differentiated from endometrial stromal cells (24). These results suggest that HMol1-8 originated from decidual cells. However, we did not examine the expression or secretion of prolactin (25-27), insulin-like growth factor binding protein $(25,27,28)$, or tissue factor $(27,29)$ which are reported markers of decidual cells. Further studies are needed to confirm the origin and characteristics of the HMol1-8 cell line.

To immortalize molar trophoblastic cells, we transduced cells with hTERT,CDK4R24C and cyclin D1, and we transduced some cells with p53C234 and MYC-2A-HRAS using recom- 

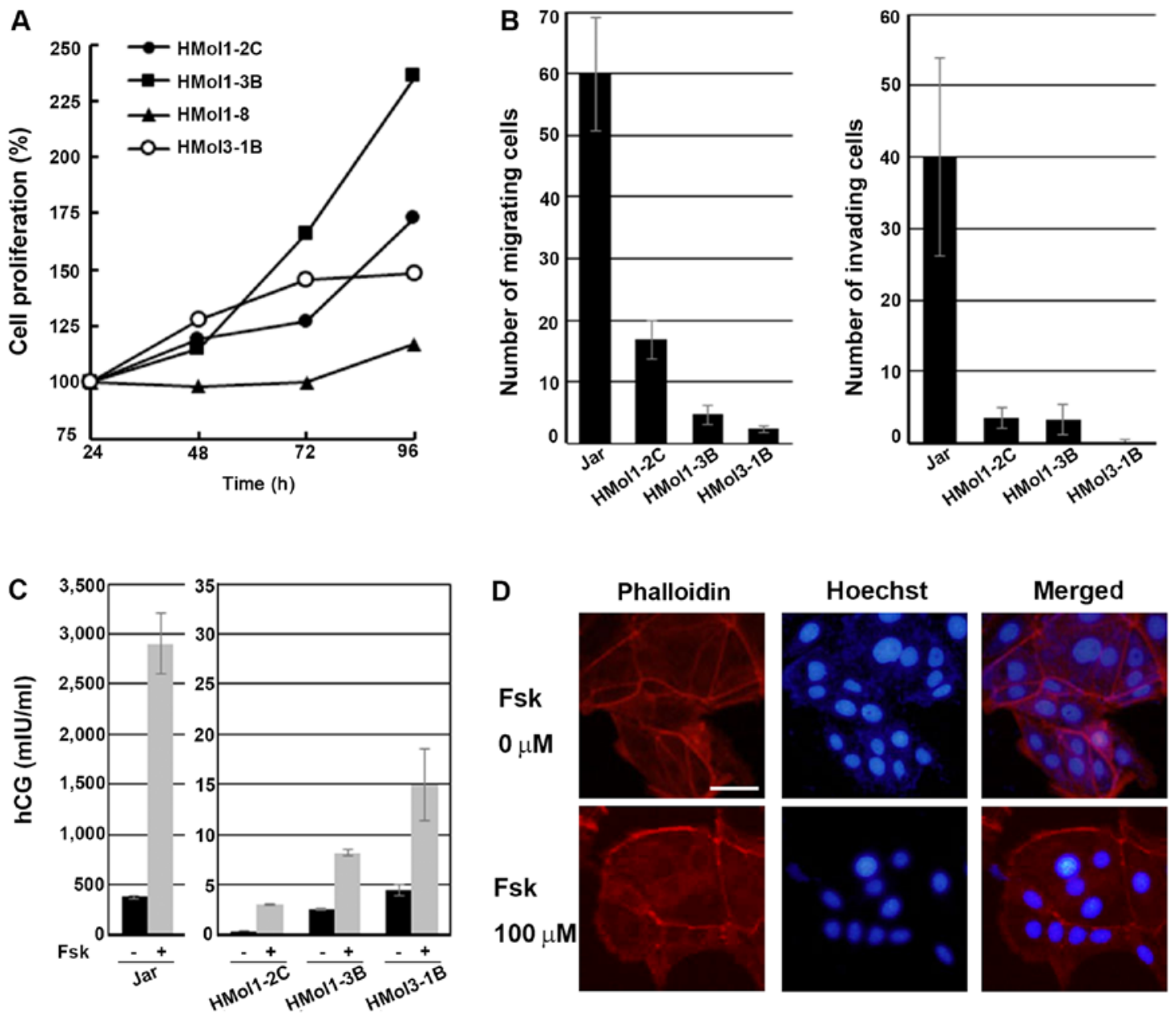

Figure 4. Assays to determine cell proliferation, migration, invasion, human chorionic gonadotropin (hCG) secretion, and the effect of forskolin treatment in established cell lines. (A) Graphical depiction of the relative absorbance readings after modified tetrazolium salt (MTS) assays, demonstrating that all established cell lines were immortal and that cell proliferation of HMol1-8 was much lower than those of HMol1-2C, HMol1-3B and HMol3-1B. Mean values of three different experiments performed in eight wells are shown. (B) Graphical depiction of data obtained from migration assays (left panel, $\mathrm{n}=3$ ) and Matrigel invasion assays (right panel, n=3) of Jar, HMol1-2C, HMol1-3B and HMol3-1B, demonstrating that the three established molar cell lines exhibited much weaker migration and invasion abilities compared to those of Jar. Data were obtained from three independent experiments. Each bar represents the mean distance of the control \pm SD. (C) Graphical depiction of data obtained from hCG assay of conditioned media of Jar, HMol1-2C, HMol1-3B and HMol3-1B with and without forskolin treatment. Data were obtained from three independent experiments, demonstrating increases in hCG secretion following forskolin treatment in HMol1-2C, HMol1-3B and HMol3-1B, as well as Jar cells. Each bar represents the mean hCG concentration (mIU/ml) \pm SD. (D) Immunofluorescent double-staining of HMol3-1B cells for nuclei (Hoechst) and the actin cytoskeleton (phalloidin), demonstrating the differentiation into multi-nucleated cells after incubation with $100 \mu \mathrm{M}$ forskolin for $48 \mathrm{~h}$. Scale bar, $50 \mu \mathrm{m}$.

binant lentiviral vectors. In previous studies, HTR-8/SVneo and B6Tert were established by transfection with SV40 large $\mathrm{T}$ antigen and hTERT while maintaining the characteristics of the parental cells, which were derived from first-trimester human EVTs and normal placental-origin cytotrophoblasts, respectively (30-32). Transduction with hTERT, CDK4R24C and cyclin D1 has been suggested to be an effective method for immortalizing normal cells with differentiation capacities while maintaining the original phenotype of the primary cells according to previous studies $(10,11,14,33-35)$. However, introduction of hTERT, CDK4R24C and cyclin D1 was not sufficient to immortalize non-luteinized granulosa cells, and adding p53C234 was effective at lengthening the lifespan of the cells (14). To immortalize cells effectively, we transfected several genes in various combinations, and we successfully established three CHM cell lines.

In this study, karyotypes of all three cell lines established from CHMs were almost tetraploid, caused by duplication of diploid progenitors. Formally, there are two major possibilities for the tetraploidization of the three cell lines: i) original diploid molar cells became tetraploid during primary culture or ii) diploid primary molar trophoblasts became tetraploid after induction of genes for immortalization. Karyotype analysis of 403 CHM samples revealed that 15 were post-zygotic tetraploids, which are likely to have developed by somatic endoreduplication of androgenic diploid cells (36). Previous studies on the immortalization of non-cancerous cell lines via the introduction of hTERT, CDK4R24C, cyclin D1 and TetOff showed intact karyotypes (10-12), except for two lines. One of these exhibited tetraploidy in $70 \%$ of cells and another showed a chromosomal deletion of chromosome 22 (33). In this study, tetraploidy may have been caused by the characteristics of the CHMs rather than being an effect of the introduction of additional genes such as p53C234, MYC and HRAS, as tetraploidy was observed in all CHM cell lines but not in HMol1-8. These results may suggest the possibility of tetraploidization during primary culture. 
There are some limitations to this study. First, the molar cell lines secretes hCG at low levels although hCG secretion is the major characteristic of hydatidiform moles. This is because differentiated cells such as syncytiotrophoblasts are more difficult to grow continuously compared with undifferentiated cells such as cytotrophoblasts, and therefore, the cell lines became cyncytiotrophoblastic after passing many times. Endogenous hCG production involves an autocrine regulation of invasion in trophoblasts (37). However, this study showed that forskolin treatment is a good method for inducing molar cell lines to increase hCG production and differentiate into syncytiotrophoblastic cells. Moreover, these cell lines may be suitable models for identifying genes that exhibit increased malignant behaviors, such as invasion or cell proliferation, together with an increase in hCG production, which is also the major characteristic of choriocarcinoma. Secondly, the molar cell lines were almost tetraploid although most CHMs are diploid. Histological morphology analysis did not reveal any differences between diploid and tetraploid CHMs (36), supporting the conclusion that the three CHM cell lines maintained the characteristics of the original molar cells.

In conclusion, we successfully established three cell lines from complete hydatidiform moles by introduction of hTERT, CDK4R24C and cyclin D1 with or without p53C234 and MYC-2A-HRAS. The genetic origins of each cell line were identical with those of the original CHM tissues, and the cell lines exhibited characteristics of trophoblastic cells, which are similar to those of undifferentiated cytotrophoblasts.

\section{Acknowledgements}

We thank Hiroyuki Miyoshi (RIKEN Tsukuba Institute) for providing the lentiviral vectors and packaging constructs. This study was supported by grant-in-aid no. 23592445 (to E.Y.) from the Japanese Ministry of Education, Culture, Sports, Science and Technology and by the National Cancer Center Research and Development Fund (23B-1). We would like to thank Editage (www.editage.jp) for English language editing.

\section{References}

1. Kajii T and Ohama K: Androgenetic origin of hydatidiform mole. Nature 268: 633-634, 1977

2. Wake N, Seki T, Fujita H, Okubo H, Sakai K, Okuyama K, Hayashi H, Shiina Y, Sato H, Kuroda M, et al: Malignant potential of homozygous and heterozygous complete moles. Cancer Res 44: 1226-1230, 1984.

3. Vejerslev LO, Dissing J, Hansen HE and Poulsen H: Hydatidiform mole: Genetic origin in polyploid conceptuses. Hum Genet 76: 11-19, 1987.

4. Ohama K, Ueda K, Okamoto E, Takenaka M and Fujiwara A Cytogenetic and clinicopathologic studies of partial moles. Obstet Gynecol 68: 259-262, 1986.

5. Kaneki E, Kobayashi H, Hirakawa T, Matsuda T, Kato H and Wake N: Incidence of postmolar gestational trophoblastic disease in androgenetic moles and the morphological features associated with low risk postmolar gestational trophoblastic disease. Cancer Sci 101: 1717-1721, 2010.

6. Seckl MJ, Sebire NJ and Berkowitz RS: Gestational trophoblastic disease. Lancet 376: 717-729, 2010.

7. Kan M, Yamamoto E, Niimi K, Tamakoshi K, Sekiya Y, Nishino K, Ino K and Kikkawa F: Gestational trophoblastic neoplasia and pregnancy outcome after routine second curettage for hydatidiform mole: A retrospective observational study. J Reprod Med 61: 373-379, 2016.
8. Taillon-Miller P, Bauer-Sardiña I, Zakeri H,Hillier L, Mutch DG and Kwok PY: The homozygous complete hydatidiform mole: A unique resource for genome studies. Genomics 46: 307-310, 1997.

9. Steinberg KM, Schneider VA, Graves-Lindsay TA, Fulton RS Agarwala R, Huddleston J, Shiryev SA, Morgulis A, Surti U, Warren WC, et al: Single haplotype assembly of the human genome from a hydatidiform mole. Genome Res 24: 2066-2076, 2014.

10. Kuroda K, Kiyono T, Eitsuka T, Isogai H, Takahashi K, Donai K, Isogai $\mathrm{E}$ and Fukuda T: Establishment of cell lines derived from the genus Macaca through controlled expression of cell cycle regulators. J Cell Biochem 116: 205-211, 2015.

11. Donai K, Kiyono T, Eitsuka T, Guo Y, Kuroda K, Sone H, Isogai E and Fukuda T: Bovine and porcine fibroblasts can be immortalized with intact karyotype by the expression of mutant cyclin dependent kinase 4, cyclin D, and telomerase. J Biotechnol 176: 50-57, 2014

12. Sasaki R, Narisawa-Saito M, Yugawa T, Fujita M, Tashiro H, Katabuchi $\mathrm{H}$ and Kiyono T: Oncogenic transformation of human ovarian surface epithelial cells with defined cellular oncogenes. Carcinogenesis 30: 423-431, 2009.

13. Okamoto T, Aoyama T, Nakayama T, Nakamata T, Hosaka T, Nishijo K, Nakamura T, Kiyono T and Toguchida J: Clonal heterogeneity in differentiation potential of immortalized human mesenchymal stem cells. Biochem Biophys Res Commun 295: 354-361, 2002.

14. Bayasula IA, Iwase A, Kiyono T, Takikawa S, Goto M, Nakamura T, Nagatomo Y, Nakahara T, Kotani T, Kobayashi H, et al: Establishment of a human nonluteinized granulosa cell line that transitions from the gonadotropin-independent to the gonadotropin-dependent status. Endocrinology 153: 2851-2860, 2012.

15. Carey BW, Markoulaki S, Hanna J, Saha K, Gao Q, Mitalipova M and Jaenisch R: Reprogramming of murine and human somatic cells using a single polycistronic vector. Proc Natl Acad Sci USA 106: 157-162, 2009.

16. Miyoshi H, Blömer U, Takahashi M, Gage FH and Verma IM: Development of a self-inactivating lentivirus vector. J Virol 72: 8150-8157, 1998.

17. Yamamoto E, Ito T, Abe A, Sido F, Ino K, Itakura A, Mizutani S, Dovat S, Nomura S and Kikkawa F: Ikaros is expressed in human extravillous trophoblasts and involved in their migration and invasion. Mol Hum Reprod 11: 825-831, 2005.

18. Yamamoto E, Ino K, Miyoshi E, Inamori K, Abe A, Sumigama S, Iwase A, Kajiyama H, Shibata K, Nawa A, et al: $\mathrm{N}$-acetylglucosaminyltransferase $\mathrm{V}$ regulates extravillous trophoblast invasion through glycosylation of alpha5beta1 integrin. Endocrinology 150: 990-999, 2009.

19. Austgulen R, Chedwick L, Vogt Isaksen C, Vatten L and Craven C: Trophoblast apoptosis in human placenta at term as detected by expression of a cytokeratin 18 degradation product of caspase. Arch Pathol Lab Med 126: 1480-1486, 2002.

20. Sasagawa M, Yamazaki T, Endo M, Kanazawa K and Takeuchi S: Immunohistochemical localization of HLA antigens and placental proteins (alpha hCG, beta hCG CTP, hPL and SP1 in villous and extravillous trophoblast in normal human pregnancy: A distinctive pathway of differentiation of extravillous trophoblast. Placenta 8: 515-528, 1987.

21. Lawler SD, Fisher RA and Dent J: A prospective genetic study of complete and partial hydatidiform moles. Am J Obstet Gynecol 164: 1270-1277, 1991.

22. Devergne O, Coulomb-L'Herminé A, Capel F, Moussa M and Capron F: Expression of Epstein-Barr virus-induced gene 3, an interleukin-12 p40-related molecule, throughout human pregnancy: Involvement of syncytiotrophoblasts and extravillous trophoblasts. Am J Pathol 159: 1763-1776, 2001.

23. Niimi K, Yamamoto E, Fujiwara S, Shinjo K, Kotani T, Umezu T, Kajiyama H, Shibata K, Ino K and Kikkawa F: High expression of $\mathrm{N}$-acetylglucosaminyltransferase IVa promotes invasion of choriocarcinoma. Br J Cancer 107: 1969-1977, 2012.

24. Zhu H, Hou CC, Luo LF, Hu YJ and Yang WX: Endometrial stromal cells and decidualized stromal cells: Origins, transformation and functions. Gene 551: 1-14, 2014.

25. Richards RG, Brar AK, Frank GR, Hartman SM and Jikihara H: Fibroblast cells from term human decidua closely resemble endometrial stromal cells: Induction of prolactin and insulinlike growth factor binding protein-1 expression. Biol Reprod 52: 609-615, 1995 .

26. Telgmann R and Gellersen B: Marker genes of decidualization: Activation of the decidual prolactin gene. Hum Reprod Update 4: 472-479, 1998 . 
27. Dunn CL, Kelly RW and Critchley HO: Decidualization of the human endometrial stromal cell: An enigmatic transformation. Reprod Biomed Online 7: 151-161, 2003.

28. Kim JJ, Jaffe RC and Fazleabas AT: Insulin-like growth factor binding protein-1 expression in baboon endometrial stromal cells: Regulation by filamentous actin and requirement for de novo protein synthesis. Endocrinology 140: 997-1004, 1999.

29. Lockwood CJ, Krikun G, Caze R, Rahman M, Buchwalder LF and Schatz F: Decidual cell-expressed tissue factor in human pregnancy and its involvement in hemostasis and preeclampsiarelated angiogenesis. Ann NY Acad Sci 1127: 67-72, 2008.

30. Graham CH, Hawley TS, Hawley RG, MacDougall JR, Kerbel RS, Khoo N and Lala PK: Establishment and characterization of first trimester human trophoblast cells with extended lifespan. Exp Cell Res 206: 204-211, 1993.

31. Wang YL, Qiu W, Feng HC, Li YX, Zhuang LZ, Wang Z, Liu Y, Zhou JQ, Zhang DH and Tsao GS: Immortalization of normal human cytotrophoblast cells by reconstitution of telomeric reverse transcriptase activity. Mol Hum Reprod 12: 451-460, 2006.

32. Li RH and Zhuang LZ: The effects of growth factors on human normal placental cytotrophoblast cell proliferation. Hum Reprod 12: 830-834, 1997.
33. Katayama M, Kiyono T, Horie K, Hirayama T, Eitsuka T, Kuroda K, Donai K, Hidema S, Nishimori K and Fukuda T: Establishment of an immortalized cell line derived from the prairie vole via lentivirus-mediated transduction of mutant cyclin-dependent kinase 4 , cyclin $\mathrm{D}$, and telomerase reverse transcriptase. Exp Anim 65: 87-96, 2016.

34. Kuroda K, Kiyono T, Isogai E, Masuda M, Narita M, Okuno K, Koyanagi Y and Fukuda T: Immortalization of fetal bovine colon epithelial cells by expression of human cyclin D1, mutant cyclin dependent kinase 4, and telomerase reverse transcriptase: An in vitro model for bacterial infection. PLoS One 10: e0143473, 2015.

35. Inagawa Y, Yamada K, Yugawa T, Ohno S, Hiraoka N, Esaki M, Shibata T, Aoki K, Saya H and Kiyono T: A human cancer xenograft model utilizing normal pancreatic duct epithelial cells conditionally transformed with defined oncogenes. Carcinogenesis 35 : 1840-1846, 2014.

36. Sundvall L, Lund H, Niemann I, Jensen UB, Bolund L and Sunde L: Tetraploidy in hydatidiform moles. Hum Reprod 28: 2010-2020, 2013.

37. Zygmunt M, Hahn D, Münstedt $\mathrm{K}$, Bischof $\mathrm{P}$ and Lang U: Invasion of cytotrophoblastic JEG-3 cells is stimulated by hCG in vitro. Placenta 19: 587-593, 1998. 